\title{
Comparison and validation exercises of the three atmospheric dispersion models in RODOS
}

\author{
J. PÄSLER-SAUER ${ }^{1}$
}

\begin{abstract}
During the EURANOS project three atmospheric dispersion models ATSTEP (ATSTEP, 2007), RIMPUFF (RIMPUFF, 1999), and DIPCOT (DIPCOT, 2009) used in the RODOS (Ehrhardt and Weis, 2000) decision support system were subject of comprehensive comparison and validation studies. The aim of the comparison exercise was a harmonisation of the models for a sample of representative, noncomplex dispersion and deposition situations in the distance range below $100 \mathrm{~km}$. Despite of different modelling and parameterisation the models should deliver similar results under these conditions. Furthermore validation studies were carried out with ATSTEP and DIPCOT using measured meteorological and contamination data from tracer dispersion field experiments. After minor model and parameter modifications final comparison calculations of the models with realistic numerical weather prediction (NWP) data have shown satisfactory consistency of the results.
\end{abstract}

\section{Introduction}

The RODOS decision support system (Ehrhardt and Weis, 2000) contains atmospheric dispersion model codes for the calculation of atmospheric transport and deposition of radioactive material released during an accident in a nuclear power plant, during transport, or from a RDD. Two operational modes are possible: diagnostic real-time on-line operation based on measured meteorological data, and prognostic operation based on numerical weather prediction data. The models are two Lagrangian puff models (ATSTEP (ATSTEP, 2007), RIMPUFF (RIMPUFF, 1999)) and a particle model (DIPCOT (DIPCOT, 2009)). All three model codes are capable of simulating atmospheric dispersion of time dependent releases and deposition to surfaces and canopy under variable meteorological and topographical conditions. Up to 25 nuclides with 4 deposition classes (noble gas, aerosol, elementary and organically bound iodine) are taken into account. Several tests and model inter-comparisons were carried out by RODOS users to approve the similarity and correctness of the results. Some results turned out to be definitely wrong; in other cases significant discrepancies between results of different models showed up. To identify the causes a systematic model intercomparison was carried out.

\footnotetext{
1 Karlsruhe Institute of Technology, Institut für Kern- und Energietechnik, Eggenstein-Leopoldshafen, Germany.
} 
TABLE I

Definition of tasks for model comparison.

\begin{tabular}{|c|c|}
\hline Location of fictive release: & KIT, Karlsruhe Research Centre, Germany. \\
\hline Activity and duration of release: & ${ }^{133} \mathrm{Xe},{ }^{131} \mathrm{I}$ elem., ${ }^{137} \mathrm{Cs}$ aerosol, each $1.0 \mathrm{e} 16 \mathrm{~Bq}$, duration $0.5 \mathrm{~h}$. \\
\hline Release height: ( 2 tasks) & $10 \mathrm{~m}$ and $150 \mathrm{~m}$ \\
\hline $\begin{array}{l}\text { Meteorological conditions: } \\
\text { wind, stability ( } 3 \text { tasks) }\end{array}$ & $\begin{array}{l}\text { Constant wind direction } 225 \text { degrees, b lowing from SW, wind speed at } \\
10 \mathrm{~m}=2 \mathrm{~m} / \mathrm{s} \text {. Pasquill-Gifford stability classes: } \mathbf{B}, \mathbf{D}, \mathbf{F}\end{array}$ \\
\hline Deposition ( 2 tasks) & dry: rain $=0 \mathrm{~mm} / \mathrm{h}$, wet: rain $=1 \mathrm{~mm} / \mathrm{h}$ all the time \\
\hline $\begin{array}{l}\text { Roughness length / surface type: } \\
\text { ( } 2 \text { tasks) }\end{array}$ & Defined by land use: agricultural and forest, both at date 1st of June \\
\hline $\begin{array}{l}\text { Results of all } 24 \text { task } \\
\text { combinations, excluding rain with } \\
\text { category B or F }\end{array}$ & $\begin{array}{l}\text { Time integrated concentration in air at } 1 \mathrm{~m} \text { height, ground contamination } \\
\left({ }^{133} \mathrm{Xe},{ }^{137} \mathrm{Cs},{ }^{131} \mathrm{I}\right) \text {, cloud gamma dose sum, and ground gamma dose rates } \\
\text { after } 10 \mathrm{~h} \text {, cloud arrival time. }\end{array}$ \\
\hline
\end{tabular}

\section{Model inter-comparison}

The basic performance of the three models was tested by comparing the results of a series of tasks. Each task consisted of a simple dispersion and deposition scenario with constant, straight line wind, plane topography, and homogeneous land-use. The tasks differed in meteorological conditions, release height, and deposition conditions, i.e. different land-use. Table I shows the full set of 24 tasks.

Moreover the models were tested under complex meteorological conditions. Numerical weather prediction data from German (DWD) and Austrian (ZAMG) weather services were used at three sites together with real topographical data:

KIT, Karlsruhe Research Centre, Germany, release height 150 m. Meteorological NWP data from DWD (2001.11.12.), strong wind shear with height, no rain;

Goesgen Nuclear Power Plant, Switzerland, release height $100 \mathrm{~m}$. Meteorological NWP data from ZAMG (2008.01.24), wind shear with height, no rain, starting time 01:00 $\mathrm{h}$.

Dukovany Nuclear Power Plant, Czech Rep., release height $100 \mathrm{~m}$, Meteorological NWP data from ZAMG (2008.01.24), wind shear with height, no rain, starting time 14:00 $\mathrm{h}$.

Following methods were used for comparison and analysis of the different models' results. Since the RODOS system produces clickable graphical output in form of plume pictures on a screen the analysis was carried out visually, by comparison of iso-lines patterns, and numerically, by relating different distance dependencies. Following types of comparisons were carried out.

Comparison of time-integrated, near ground air contamination fields of ${ }^{133} \mathrm{Xe}$ (TIC, Bq.s $/ \mathrm{m}^{3}$ ) for different stabilities, release heights, and roughness lengths (i.e., 
land-use): This shows directly geometrical differences due to dilution during dispersion, because deposition and depletion effects do not occur, and radioactive decay can be neglected. It allows for inference to differences in diffusion parameters.

Comparison of dry and wet deposited activity fields of aerosol ${ }^{137} \mathrm{Cs}$ and elementary ${ }^{131}$ I for different land-use and release heights, in relation to ${ }^{133} \mathrm{Xe}$ TIC: This shows differences in deposition to canopy and related depletion of the activity cloud with distance.

Comparison of cloud arrival times: Shows differences of the effective transport velocity of activity.

Comparison of gamma doses from cloud, in relation to ${ }^{133} \mathrm{Xe}$ TIC: Shows differences in calculation of cloud gamma fields.

\section{Results}

The first comparison runs showed in general similar looking results, although there were some particular cases with strong deviations. The analysis of these deviations has shown three types of reasons: model coding errors (1); values of model parameters (2); and model specific applicability limitations (3).

In the first two cases the model/code authors were informed, and a corrected or modified version was requested, finally yielding satisfactory results. Following modifications were carried out:

ATSTEP: calculation of representative height of wind vectors for puff transport was upgraded.

RIMPUFF: an error in plume rise calculation was detected (outside of the frame of comparison calculations) and was eliminated by the code authors.

DIPCOT: Some problems with dry deposition of elementary iodine occurred, i.e. depletion of the cloud was unrealistically high. Some horizontal plume widths appeared to be too narrow. Both effects were corrected by the code author.

\section{Case 3, model specific applicability limitations}

When tested under complex meteorological conditions together with real topographical data the particle model DIPCOT shows a certain advantage over the puff models. The wind data used contain strong directional wind shift with height. A particle model can account for this and can disperse a fraction of the particles 

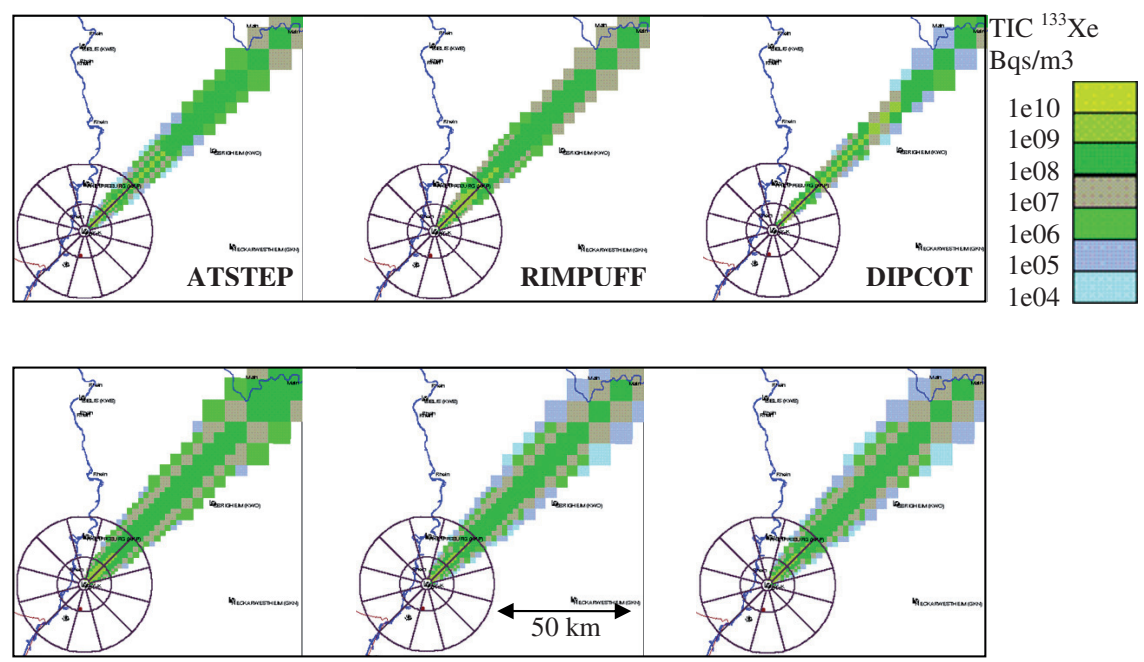

Figures 1 - Time integrated ${ }^{133}$ Xe concentration in air near ground, PG-category D, release height $10 \mathrm{~m}$, agricultural land-use (a), forest (b). Except of the DIPCOT plume (a) which is a bit narrow there are only minor deviations in the other cases.

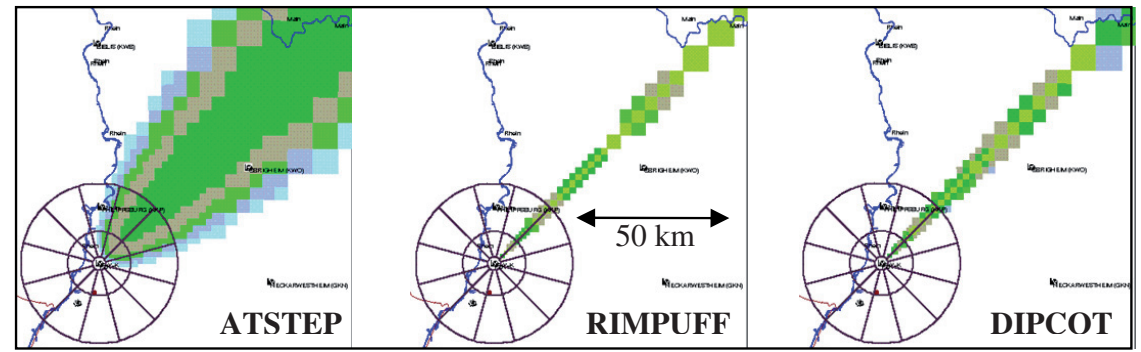

Figure 2 - Time integrated ${ }^{133}$ Xe concentration in air near ground, PG-category $F$, release height $10 \mathrm{~m}$, very rough terrain. The ATSTEP plume is much wider than the other ones. The reason for this is that ATSTEP uses here horizontal dispersion parameters derived from measurements (Karlsruhe-Jülich parameters) which contain hourly integrated meandering of the wind vector. The other two model parameters do not include meandering, only turbulent diffusion. Under stable category F conditions both cases can occur.

released into shifted directions. In Figure 3 the wind blows from SW at $100 \mathrm{~m}$ height, turning to $\mathrm{N}$ at $400 \mathrm{~m}$ (light blue area in Fig. 3, DIPCOT results). The areas with maximum contamination or dose however look similar to the areas calculated with the puff models (green and dark blue areas in Figs. 3 and 4). Figure 4 demonstrates that all three models show a satisfactory result concerning the main 


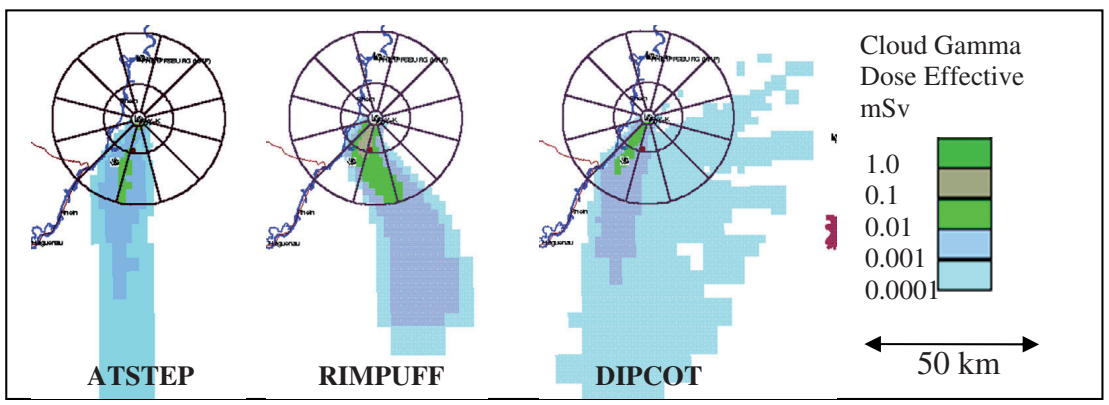

Figure 3 - KIT, Karlsruhe Research Centre, Germany, release height $150 \mathrm{~m}$. Cloud gamma doses.

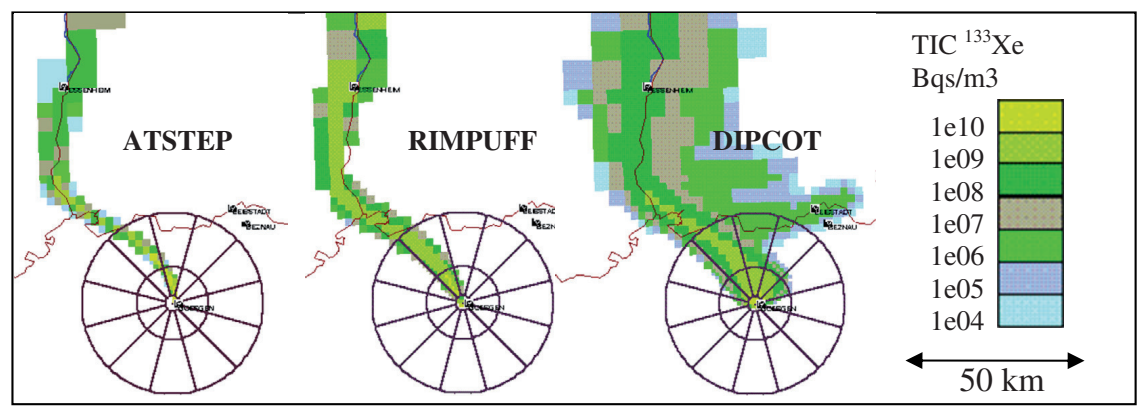

Figure 4 - Goesgen Nuclear Power Plant, Switzerland, release height $100 \mathrm{~m} . \mathrm{TIC}^{133}{ }^{\mathrm{Xe}}$.

transport trajectories. The release starting from Goesgen NPP is blown into the northern upper Rhine valley. Additionally the DIPCOT model shows some shear transport to the East, with a small plume into the eastern upper Rhine valley.

\section{Model validation}

Data from Kinkaid, Indianapolis, and Copenhagen field measurements (Olesen and Chang, 2005) were used for validation studies with ATSTEP and DIPCOT. The Kincaid and Indianapolis data sets are based on tracer releases from large coal fired power plants and therefore contain thermal plume rise. The Copenhagen data are based on cold tracer releases. All data were taken from the Model Validation Kit (Model Validation Kit, 2007).

For the validation calculations with ATSTEP (Model Validation Kit, 2007) the hourly meteorological data of a measuring run were put in interactively, also 


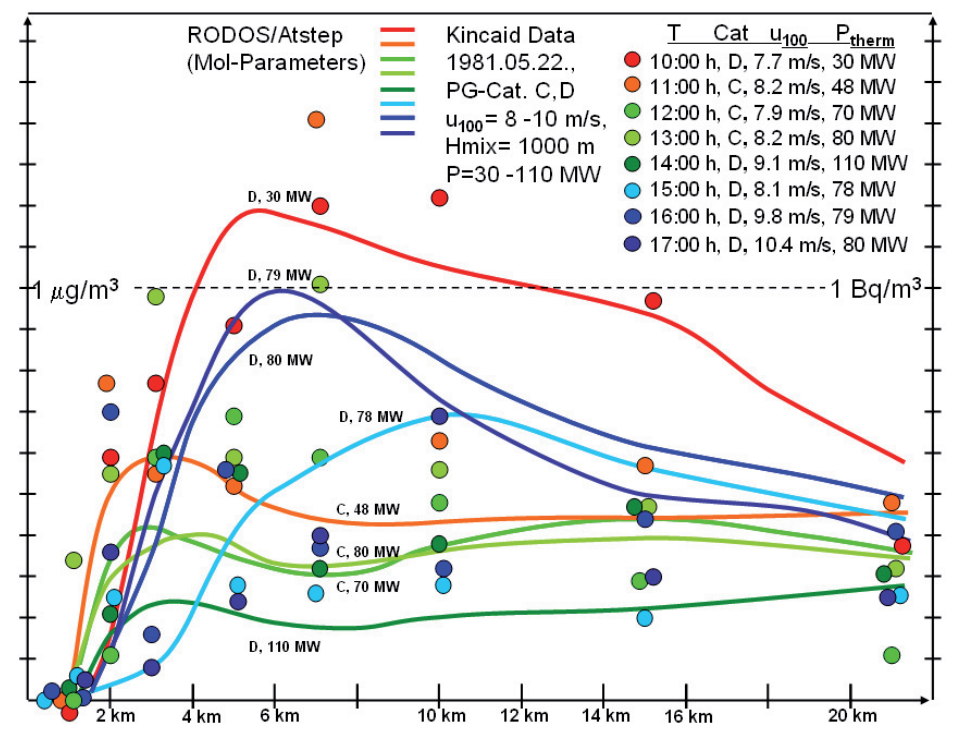

Figure 5 - Kincaid data and ATSTEP results.

hourly source term and release data. A measured release rate of the $\mathrm{SF}_{6}$ tracer in $\mathrm{g} / \mathrm{s}$ was substituted in RODOS by a release of the radioactive noble gas ${ }^{133} \mathrm{Xe}$ in $\mathrm{MBq} / \mathrm{s}$, i.e. a measured near ground air contamination of $1 \mathrm{mg} / \mathrm{m}^{3}$ of $\mathrm{SF}_{6}$ corresponds to a calculated value of $1 \mathrm{~Bq} / \mathrm{m}^{3}$ of ${ }^{133} \mathrm{Xe}$. Figure 5 shows an example result of the Kincaid power plant (stack release height $187 \mathrm{~m}$ ) validation study. The tracer release lasted for 8 hours. Hourly varying wind speed and strongly fluctuating releases of thermal power led to variable plume rise and correspondingly to variable near ground tracer concentrations (coloured dots). The ATSTEP calculation gave satisfactory results (coloured curves); the vertical axes are linear, maximum differences are below a factor of 3 .

Figure 6 shows an example result of the Indianapolis power plant (stack release height $84 \mathrm{~m}$ ) validation study. The tracer release lasted for 7 hours. Wind speed at stack height was about $6 \mathrm{~m} / \mathrm{s}$ and the release of thermal power $23 \mathrm{MW}$ (coloured dots). Also here the ATSTEP calculation gave satisfactory results (coloured curves).

Figure 7 shows a result of the Copenhagen study (tower release height $115 \mathrm{~m}$ ). The measured horizontal plume width parameters $\sigma_{\mathrm{y}}(\mathrm{x})$ (black dots) were compared with both the Karlsruhe-Jülich (KJ) and the Mol parameters used by 


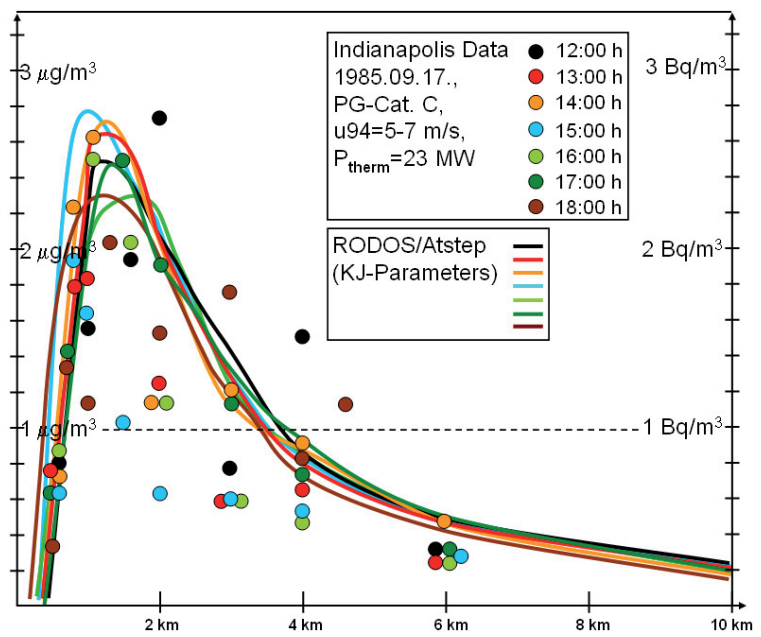

Figure 6 - Indianapolis data and ATSTEP results.

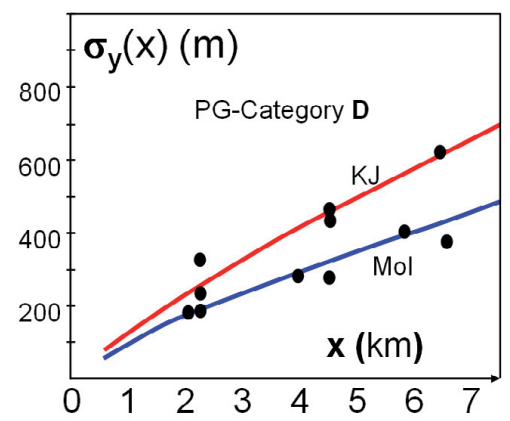

Figure 7 - Copenhagen data and ATSTEP results.

ATSTEP. The Copenhagen measurements were carried out in a suburban area and therefore it is correct that the data lie between the red KJ-curve for urban areas with high roughness length and the blue Mol-curve for more rural conditions. The particle model DIPCOT (Andronopoulos et al., 1999) also used the Copenhagen data set for adjusting its horizontal diffusion parameters, in addition, Indianapolis and Prairie Grass data were also used for this purpose.

\section{Conclusions}

The results of this study show that all three dispersion models in the RODOS system show similar and realistic results under simple and moderately complex 
meteorological situations. Under complex conditions the particle model DIPCOT has the greatest potential for realistic results.

Acknowledgment. This work has received partial financial support from the European Commission Sixth Framework Programme (Nuclear Fission/Radiation Protection) under the EURANOS integrated project: European approach to nuclear and radiological emergency management and rehabilitation strategies (Contract No: FI6R-CT-2004-508843).

\section{REFERENCES}

Andronopoulos S., Davakis E., Bertzis J.G., Kovalets I. (2010) RODOS meteorological pre-processor and atmospheric dispersion model DIPCOT: a models suite for radionuclides dispersion in complex terrain, Radioprotection, 45, S77-S84.

ATSTEP model description (2007) Internet: http://www.rodos.fzk.de/Documents/Public/HandbookV6f/Volume3/ATSTEPfinal2.pdf.

DIPCOT model description (2009) Internet: http://www.rodos.fzk.de/Documents/Public/HandbookV6f/Volume3/RA2TN0901_DIPCOT.pdf.

Ehrhardt, J., Weis, A., (eds). RODOS: Decision Support System for Off-site Nuclear Emergency Management in Europe. European Commission, Brussels, Report EUR 19144, 2000.

Model Validation Kit (2007), Internet: http://www.harmo.org/kit/

Olesen H.R., Chang J.C., Consolidating Tools For Model Evaluation, , Paper presented at the 10th international conference on Harmonisation within Atmospheric Dispersion Modelling for Regulatory Purposes, Sissi, Crete, October 17-20, 2005. The entire manuscript (extended abstract) is available at http://harmo.org/Docs/OlesenChang.pdf.

Päsler-Sauer J. Validation Studies with RODOS/Atstep, Proceedings of the 11th Intern. Conf. on Harmonization within Atmospheric Dispersion Modelling for Regulatory Purposes, Cambridge, 2007. Internet:

http://harmo.org/conferences/proceedings/_Cambridge/publishedSections/Pp078-082.pdf.

RIMPUFF model description (1999) Internet:

http://www.rodos.fzk.de/Documents/Public/HandbookV5/Volume3/4_2_6_RIMPUFF.pdf. 